\title{
CONFORMANCE IMPROVEMENT USING GELS
}

Semi-Annual Technical Progress Report,

Reporting Period: June 20, 2001 through December 19, 2001

Principal Author: $\quad$ Randall S. Seright

(505) 835-5571

Report Date: $\quad$ April 2002

DOE Award Number: $\quad$ DE-FC26-01BC15316

Name and Address of Submitting Organization:

New Mexico Petroleum Recovery Research Center

New Mexico Institute of Mining and Technology

Socorro, New Mexico 87801

NM PRRC Contributors: Richard Schrader, John Hagstrom II, Ying Wang, Abdullah Al-Dhafeeri

Intevep/PDVSA Contributor: Amaury Marin

PRRC Report 02-07 


\title{
DISCLAIMER
}

This report was prepared as an account of work sponsored by an agency of the United States Government. Neither the United States Government nor any agency thereof, nor any of their employees, makes any warranty, expressed or implied, or assumes any legal liability or responsibility for the accuracy, completeness, or usefulness of any information, apparatus, product, or process disclosed, or represents that its use would not infringe privately owned rights. Reference herein to any specific commercial product, process, or service by trade name, trademark, manufacturer, or otherwise does not necessarily constitute or imply its endorsement, recommendation, or favoring by the United States Government or any agency thereof. The views and opinions of authors expressed herein do not necessarily state or reflect those of the United States Government.

\begin{abstract}
This technical progress report describes work performed from June 20 through December 19, 2001, for the project, "Conformance Improvement Using Gels." Interest has increased in some new polymeric products that purport to substantially reduce permeability to water while causing minimum permeability reduction to oil. In view of this interest, we are currently studying BJ's Aqua Con. Results from six corefloods revealed that the Aqua Con gelant consistently reduced permeability to water more than that to oil. However, the magnitude of the disproportionate permeability reduction varied significantly for the various experiments. Thus, as with most materials tested to date, the issue of reproducibility and control of the disproportionate permeability remains to be resolved.
\end{abstract}

Concern exists about the ability of gels to resist washout after placement in fractures. We examined whether a width constriction in the middle of a fracture would cause different gel washout behavior upstream versus downstream of the constriction. Tests were performed using a formed $\mathrm{Cr}$ (III)-acetate-HPAM gel in a 48-in.-long fracture with three sections of equal length, but with widths of 0.08-, 0.02-, and 0.08-in., respectively. The pressure gradients during gel extrusion (i.e., placement) were similar in the two 0.08-in.-wide fracture sections, even though they were separated by a 0.02 -in.-wide fracture section. The constriction associated with the middle fracture section may have inhibited gel washout during the first pulse of brine injection after gel placement. However, during subsequent phases of brine injection, the constriction did not inhibit washout in the upstream fracture section any more than in the downstream section.

\section{TABLE OF CONTENTS}

Disclaimer ii

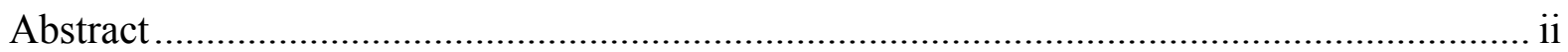

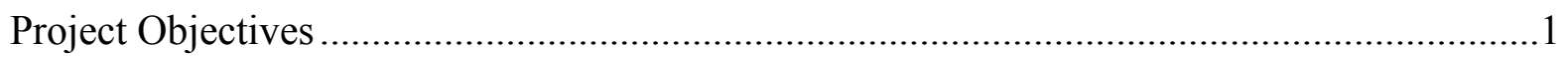

Disproportionate Permeability Reduction - Aqua Con ...........................................................

Gel Properties in Fractures-Effect of Constrictions on Washout............................................2

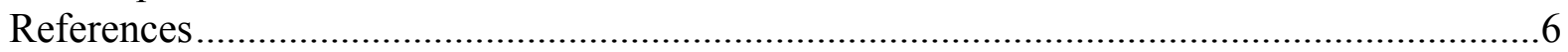




\section{PROJECT OBJECTIVES}

This research project has two objectives. The first objective is to identify gel compositions and conditions that substantially reduce flow through fractures that allow direct channeling between wells, while leaving secondary fractures open so that high fluid injection and production rates can be maintained. This goal will be reached by (1) characterizing gel propagation through fractures as a function of fracture width, length, and height, injection rate, gel composition, and temperature, (2) correlating rheology in fractures with that in a viscometer, and (3) using the experimental results to develop an appropriate model for gel placement and treatment sizing.

The second objective is to optimize treatments in fractured production wells, where the gel must reduce permeability to water much more than that to oil. Within this objective, the specific goals are to (1) determine the correct mechanism(s) for the disproportionate permeability reduction, (2) identify conditions that maximize the phenomenon, (3) find materials and methods that make the phenomenon predictable and controllable, and (4) establish a methodology to determine how much gelant should be injected in a given fractured production well.

\section{DISPROPORTIONATE PERMEABILITY REDUCTION-AQUA CON}

Interest has increased in some new polymeric products that purport to substantially reduce permeability to water while causing minimum permeability reduction to oil. We are currently studying one of these products-BJ's Aqua Con. To date, we performed six corefloods using $6 \%$ Aqua Con in a $2 \% \mathrm{KCl}$ brine (at room temperature). Four of the floods were performed in strongly water-wet Berea sandstone cores, while two were conducted in strongly oil-wet polyethylene cores. Properties of the cores and results from the floods are summarized in Tables 1 and 2 . In each flood, absolute permeability $(k), k_{r o}$, and $k_{r w}$ values were established before gelant injection. Next, roughly $10 \mathrm{PV}$ of Aqua Con gelant were injected using pressure gradients that did not mobilize residual oil. After gelant placement, oil (a mixture of $85 \%$ hexadecane and $15 \%$ 1-bromohexadecane) was injected to determine the oil residual resistance factors $\left(F_{\text {rro }}\right)$, and brine $(2 \% \mathrm{KCl})$ was injected to determine the water residual resistance factors $\left(F_{r r w}\right)$. For two of the floods in Berea (Cores 342 and 346), oil was injected first after gelant placement, followed by cycles of water and oil injection (to obtain $F_{r r o 1}, F_{r r w 1}, F_{r r o 2}$, and $F_{r r w 2}$ in Table 1). For the other two Berea corefloods (Cores 343 and 345) after gelant placement, water was injected first, followed by cycles of oil and water injection (to obtain $F_{r r w 1}, F_{r r o 2}$, and $F_{r r w 2}$ ). Similarly, for one of the polyethylene cores (Core 341) after gelant placement, oil was injected first, while water was injected first for the other coreflood (Core 344).

Results from the six corefloods revealed that the Aqua Con gelant consistently reduced permeability to water more than that to oil. However, the magnitude of the disproportionate permeability reduction varied significantly for the various experiments. In Berea, $F_{\text {rro }}$ values ranged from 3.2 to 22.6 , while $F_{r r w}$ values ranged from 11.4 to 314 . Thus, as with most materials tested to date, the issue of reproducibility and control of the disproportionate permeability reduction remains to be resolved. Some factors that may play a role here include core mineralogy, absolute core permeability, residual fluid saturations and permeabilities before gelant placement, and order of water/oil post-floods. We note that the range of $F_{r r}$ values appeared tighter for the polyethylene corefloods (Table 2). 
Table 1-Floods in Berea Sandstone Cores

\begin{tabular}{|c|c|c|c|c|c|c|c|}
\hline Core & $k$, darcys & $k_{r o}$ & $k_{r w}$ & $F_{r r o 1}$ & $F_{r r w 1}$ & $F_{r r o 2}$ & $F_{r r w 2}$ \\
\hline 342 & 0.85 & 0.91 & 0.28 & 22.6 & 314 & 21.8 & \\
\hline 343 & 0.83 & 0.85 & 0.27 & & 11.4 & 13.3 & 41 \\
\hline 345 & 0.58 & 0.68 & 0.096 & & 246 & 8.7 & 127 \\
\hline 346 & 0.75 & 0.60 & 0.064 & 4.2 & 52.0 & 3.2 & 29.5 \\
\hline
\end{tabular}

Table 2-Floods in Polyethylene Cores

\begin{tabular}{|c|c|c|c|c|c|c|c|}
\hline Core & $k$, darcys & $k_{r o}$ & $k_{r w}$ & $F_{r r o 1}$ & $F_{r r w 1}$ & $F_{r r o 2}$ & $F_{r r w 2}$ \\
\hline 341 & 6.4 & 0.49 & 0.62 & 1.5 & 4.0 & 1.8 & \\
\hline 344 & 10.1 & 0.30 & 0.36 & & 6.2 & 1.5 & 5.0 \\
\hline
\end{tabular}

From the vendor's viewpoint, one could argue that our floods were not a fair test of Aqua Con, since we did not exactly follow the vendor's recommended flooding procedure. In particular, they recommended (1) preflushing the core with $2 \% \mathrm{KCl}, 0.2 \% \mathrm{NE}-940,10 \%$ US-40, (2) injecting the gelant containing $2 \% \mathrm{KCl}, 0.2 \% \mathrm{NE}-940,6 \%$ Aqua Con, and (3) postflushing with $2 \% \mathrm{KCl}, 0.2 \% \mathrm{NE}-940$. US- 40 is a BJ product that contains ethylene glycol monobutyl ether. NE-940 is a BJ product that contains $40-70 \%$ methanol, 5-10\% 2-ethylhexanol, 5-10\% isopropanol, $1-5 \%$ ethoxylated alcohol, and $5-10 \%$ heavy aromatic naptha. We attempted two corefloods using the BJ-recommended procedure; however, substantial volumes of oil were mobilized during gelant injection - even at low pressure gradients. We suspect that the alcohols and ether present in US-40 and NE-940 were responsible for oil mobilization. Because oil mobilization compromised the determination of residual resistance factors, we decided not to use US-40 and NE-940 — at least, not for our initial studies.

Of course, an important premise of our research project is that the disproportionate permeability reduction could be made more reproducible and controllable if we understood the mechanism behind the phenomenon. Therefore, we performed X-ray computed microtomography studies (specifically on Core 346 in Table 3). When the imaging analyses become available, comparisons will be made to the mechanism observed using a $\mathrm{Cr}(\mathrm{III})$-acetate-HPAM gel. ${ }^{1}$

\section{GEL PROPERTIES IN FRACTURES-EFFECT OF CONSTRICTIONS ON WASHOUT}

In many field applications, gel treatments were less effective than expected in reducing water production from fractured wells. Concern exists about the ability of gels to resist washout after placement. In our previous quarterly report, ${ }^{2}$ we described several experiments where the pressure gradient for washout during brine injection was similar to or less than the pressure gradient observed during gel placement (extrusion) in the fracture. The fractures in these experiments were of relatively uniform width for the entire length of the fracture. We wondered whether gel washout would be less severe if a significant constriction occurred within the fracture. To explore this possibility, an experiment was performed using a 48 -in.-long fracture where the fracture width was $0.08 \mathrm{in}$. $(2 \mathrm{~mm})$ in the first 16-in.-long section, $0.02 \mathrm{in} .(0.5 \mathrm{~mm})$ in the second 16-in.-long section, and 0.08 in. in the final 16-in.-long section. The cross-sectional area of the Berea sandstone core that contained the fracture was about 1.5 in. x 1.5 in. 
We injected 3.7 liters of one-day-old Cr(III)-acetate-HPAM gel (0.5\% Alcoflood 935, 0.0417\% $\mathrm{Cr}(\mathrm{III})$-acetate, $\left.1 \% \mathrm{NaCl}, 0.1 \% \mathrm{CaCl}_{2}\right)$ using a rate of $2,000 \mathrm{~cm}^{3} / \mathrm{hr}$. After gel placement, the core was shut in for one day. (These experiments were performed at $41^{\circ} \mathrm{C}$.) Next, brine $(1 \%$ $\mathrm{NaCl}, 0.1 \% \mathrm{CaCl}_{2}$ ) was injected at a low rate (i.e., $100 \mathrm{~cm}^{3} / \mathrm{hr}$ ). After recording the pressure gradient, the brine injection rate was doubled, and the measurements were repeated. This process was repeated in stages up to a final brine injection rate of $16,000 \mathrm{~cm}^{3} / \mathrm{hr}$. Then the brine injection rate was decreased in stages.

Table 3 and Figs. 1 and 2 summarize some of the results. During gel injection, the pressure gradient quickly stabilized at values of $5.0 \mathrm{psi} / \mathrm{ft}$ in the first fracture section and $4.9 \mathrm{psi} / \mathrm{ft}$ in the third fracture section. (See Fig. 1 and the first data column of Table 3.) Thus, the pressure gradients during gel extrusion were similar in the two 0.08 -in.-wide sections, even though they were separated by a 0.02-in.-wide fracture section. This result was consistent with an earlier experiment. ${ }^{3}$ In the 0.02 -in.-wide section of the fracture, the pressure gradient stabilized at 19.5 $\mathrm{psi} / \mathrm{ft}$. Consistent with our earlier work, ${ }^{3}$ the pressure gradient for gel extrusion increased with decreasing fracture width.

Table 3-Pressure Gradients during Gel and Brine Injection into a 48-in.-Long Fracture with Variable Width.

\begin{tabular}{|c|c|c|c|}
\hline $\begin{array}{c}L_{f} \times w_{f} \\
\text { in. } \times \text { in. }\end{array}$ & $\begin{array}{c}\text { Gel average, } \\
\mathrm{psi} / \mathrm{ft}\end{array}$ & $\begin{array}{c}\text { Brine peak, } \\
\mathrm{psi} / \mathrm{ft}\end{array}$ & $\begin{array}{c}\text { Final brine, } \\
\mathrm{psi} / \mathrm{ft}\end{array}$ \\
\hline $16 \times 0.08\left(1^{\text {st }}\right.$ section $)$ & 5.0 & 9.6 & 0.6 \\
\hline $16 \times 0.02\left(2^{\text {nd }}\right.$ section $)$ & 19.5 & 6.9 & 2.6 \\
\hline $16 \times 0.08\left(3^{\text {rd }}\right.$ section $)$ & 4.9 & 3.2 & 0.9 \\
\hline
\end{tabular}

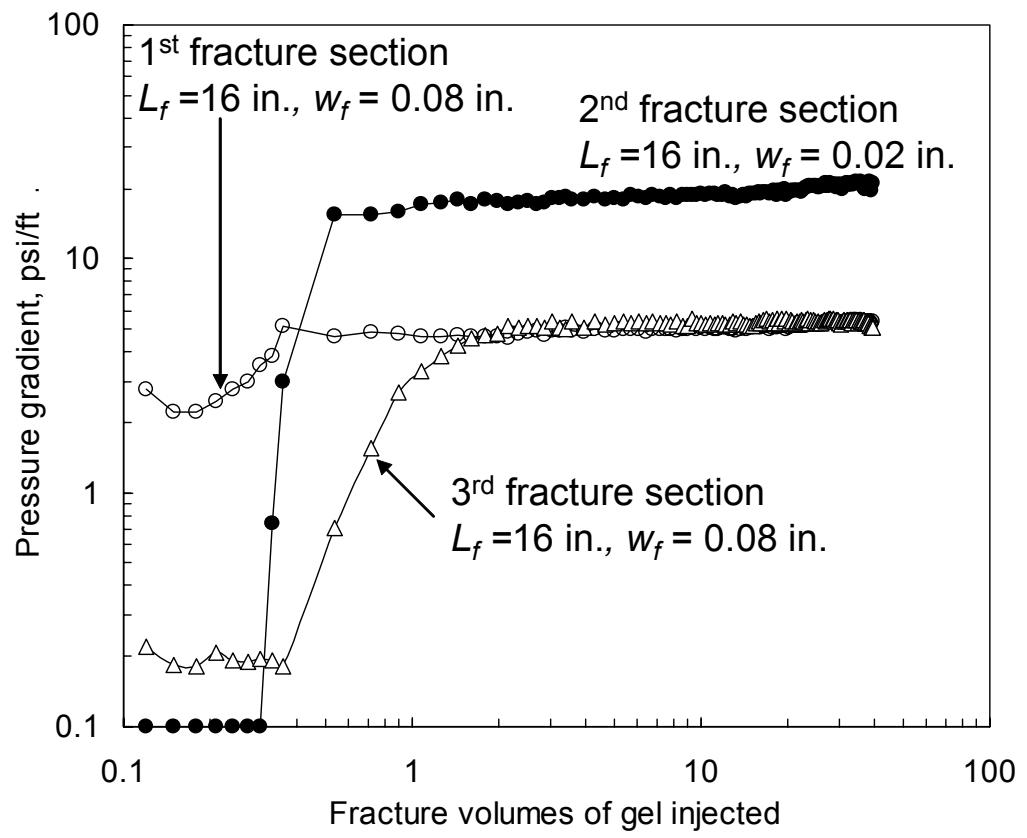

Fig. 1-Pressure gradients during injection of a $\mathrm{Cr}(\mathrm{III})$-acetate-HPAM gel $\left(2,000 \mathrm{~cm}^{3} / \mathrm{hr}\right)$. 
The second data column of Table 3 lists the peak pressure gradients observed during the first brine injection (at $100 \mathrm{~cm}^{3} / \mathrm{hr}$ ) after gel placement. In the first fracture section, the pressure gradient rose rapidly to $9.6 \mathrm{psi} / \mathrm{ft}$ (within 0.15 fracture volumes of brine injection), followed by a rapid decrease ultimately to $0.6 \mathrm{psi} / \mathrm{ft}$ after 1.3 fracture volumes. A spurious secondary peak was observed at 1 fracture volume - suggesting additional gel mobilization and dislodging (Fig. 2). The peak pressure gradients were $6.9 \mathrm{psi} / \mathrm{ft}$ in the second fracture section and $3.2 \mathrm{psi} / \mathrm{ft}$ in the third section. It is interesting that the primary pressure peaks diminished in magnitude by about 3 $\mathrm{psi} / \mathrm{ft}$ sequentially through the three sections. One might have expected the largest pressure peak to be observed in the second (and most narrow) section. For the three sections, the primary pressure peaks were observed at about the same time (i.e., 0.15 to 0.18 fracture volumes of brine injection-see Fig. 2). This result indicates that gel failure occurred simultaneously in all three fracture sections.

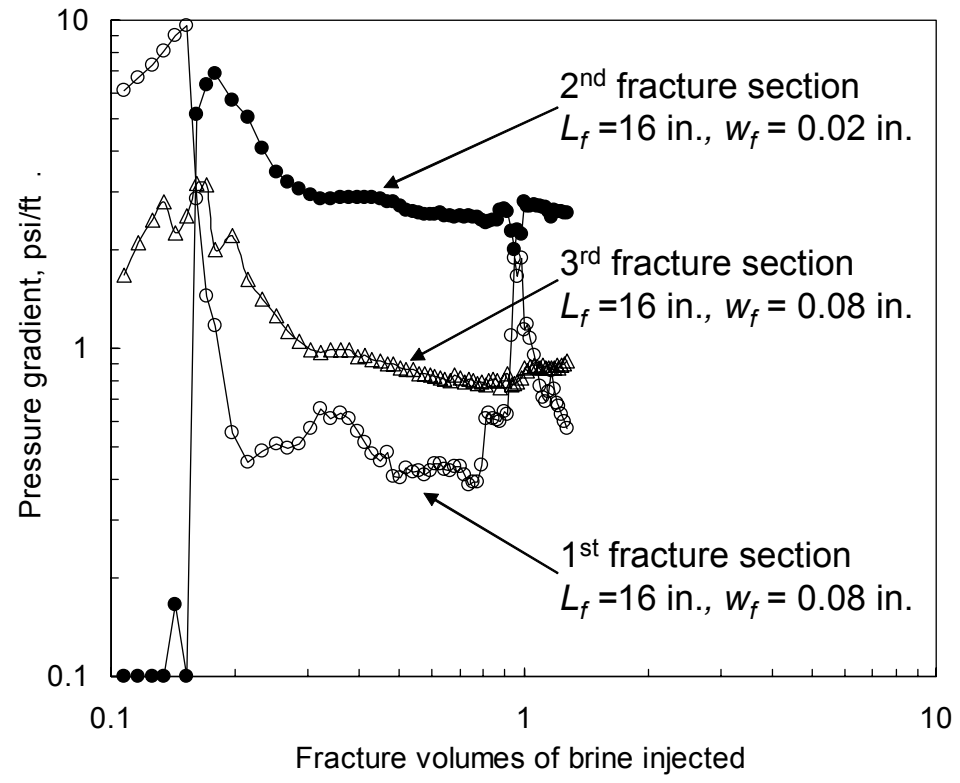

Fig. 2-Pressure gradients during brine injection after gel placement $\left(100 \mathrm{~cm}^{3} / \mathrm{hr}\right)$.

For the first fracture section, the peak pressure gradient during brine injection $(9.6 \mathrm{psi} / \mathrm{ft}$ from Table 3) was almost twice the average pressure gradient during gel injection (5 psi/ft). Based on previous work, ${ }^{2}$ we expected that the pressure gradient for gel mobilization during brine injection would be about the same as that during gel injection. Thus, the constriction associated with the middle fracture section may have inhibited gel washout during the first phase of brine injection. Interestingly, however, in the second fracture section, the peak brine pressure gradient was only about one-third of the average pressure gradient during gel injection (6.9 versus 19.5 psi/ft, from Table 3).

During gel placement, mobile gel (with the same composition as the injected gel) forms wormholes through a much more concentrated immobile (dehydrated) gel in the fracture. ${ }^{2}$ Presumably, during brine injection after gel placement, the gel in these wormholes provided the point of failure. ${ }^{2}$ This presumption was qualitatively consistent with the pressure gradients noted 
near the end of brine injection. Standard calculations for laminar flow of brine in tubes or slits ${ }^{4}$ (coupled with the brine pressure gradients and flow rates) suggested that less than $2 \%$ of the gel washed out during brine injection. In contrast, if the entire gel mass had washed out, the brine pressure gradients should have been lower by at least a factor of 300 in the 0.02 -in.-wide section of the fracture and by at least a factor of 10,000 in the 0.08-in.-wide sections of the fracture. Also, at the end of the experiment (i.e., after the rate studies described below), the fracture was opened-revealing that most of the fracture was filled with concentrated gel.

The average pressure gradients during brine injection at other rates are shown in Fig. 3. The behavior in the third fracture section closely tracked that in the first section-indicating that the degree of gel washout was similar in both 0.08-in.-wide fracture sections. In the above discussion of Table 3, we suggested that the constriction associated with the middle fracture section may have inhibited gel washout during the first phase of brine injection. Evidently, during the subsequent phases of brine injection (at higher rates), the constriction did not inhibit washout in the upstream fracture section any more than in the downstream section.

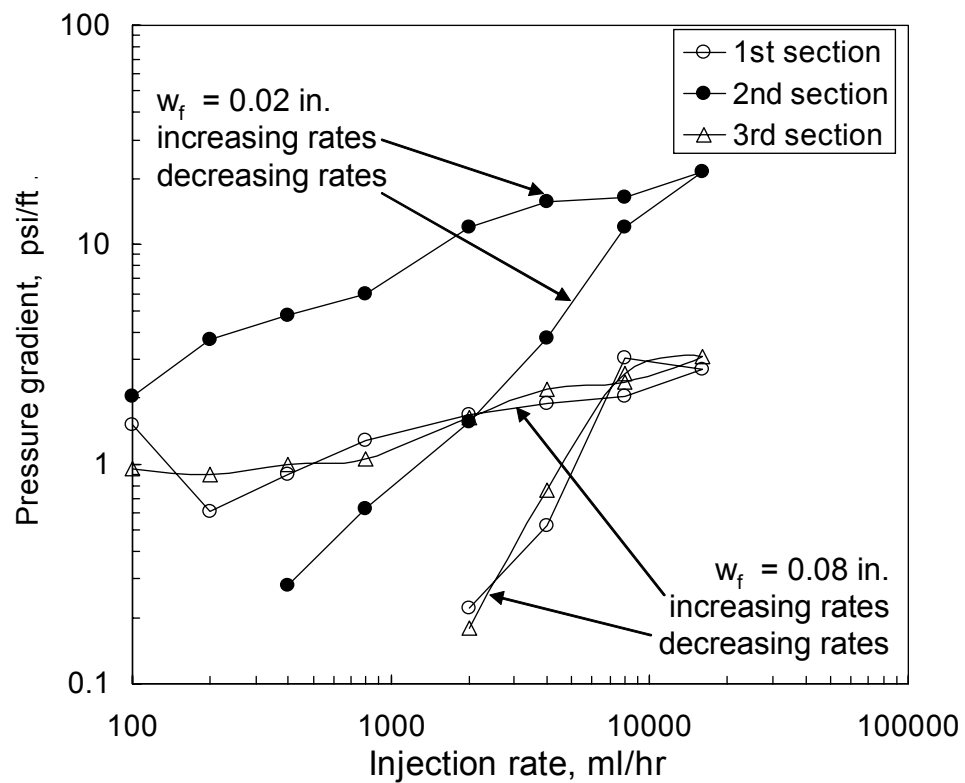

Fig. 3-Pressure gradients versus brine injection rate after gel placement.

In all fracture sections, the pressure gradients consistently increased with increased brine injection rate. If the brine flow paths (i.e., the open wormholes) were of fixed size, the pressure gradient should be directly proportional to the brine injection rate. For the increasing rate sequence in the middle fracture (solid symbols in Fig. 3), the pressure gradient varied with rate raised to the 0.5 power. Since the rate exponent was less than unity, the flow paths became progressively more open with increased rate. For comparison, in the first and third fracture sections (open symbols in Fig. 3), pressure gradients varied with rate raised to the 0.25 power. These results revealed that increased brine rates widened the flow openings to a proportionately greater extent in the 0.08 -in.-wide fractures then in the 0.02 -in.-wide fracture. 
For all fracture sections, when the rates were decreased in stages, pressure gradients varied with rate raised approximately to the first power. This result indicated no further erosion of the wormhole pathways when subjected to diminishing brine injection rates.

During brine injection after gel placement, if we assume that all flow occurs through a single cylindrical wormhole, the diameter of that flow path can be estimated using the pressure drop and rate information. ${ }^{4}$ Fig. 4 shows these calculated diameters for the three fracture sections during the increasing sequence of brine injection rates. For the middle fracture section, the calculated wormhole diameter rose from $0.007 \mathrm{in}$. at the lowest rate to $0.014 \mathrm{in}$. at the highest rate. Thus, the effective wormhole width remained less than the fracture width (0.02 in.). For comparison, in the 0.08-in.-wide fracture sections, the calculated wormhole diameters were about the same at the lowest rate $\left(100 \mathrm{~cm}^{3} / \mathrm{hr}\right)$ as that in the 0.02 -in.-wide section (i.e., $0.008 \mathrm{in}$. versus 0.007 in.). However, as the brine injection rate increased in the 0.08 -in.-wide sections, the wormhole diameters increased proportionately more - from $0.008 \mathrm{in}$. at the lowest rate to 0.023 in. at the highest rate.

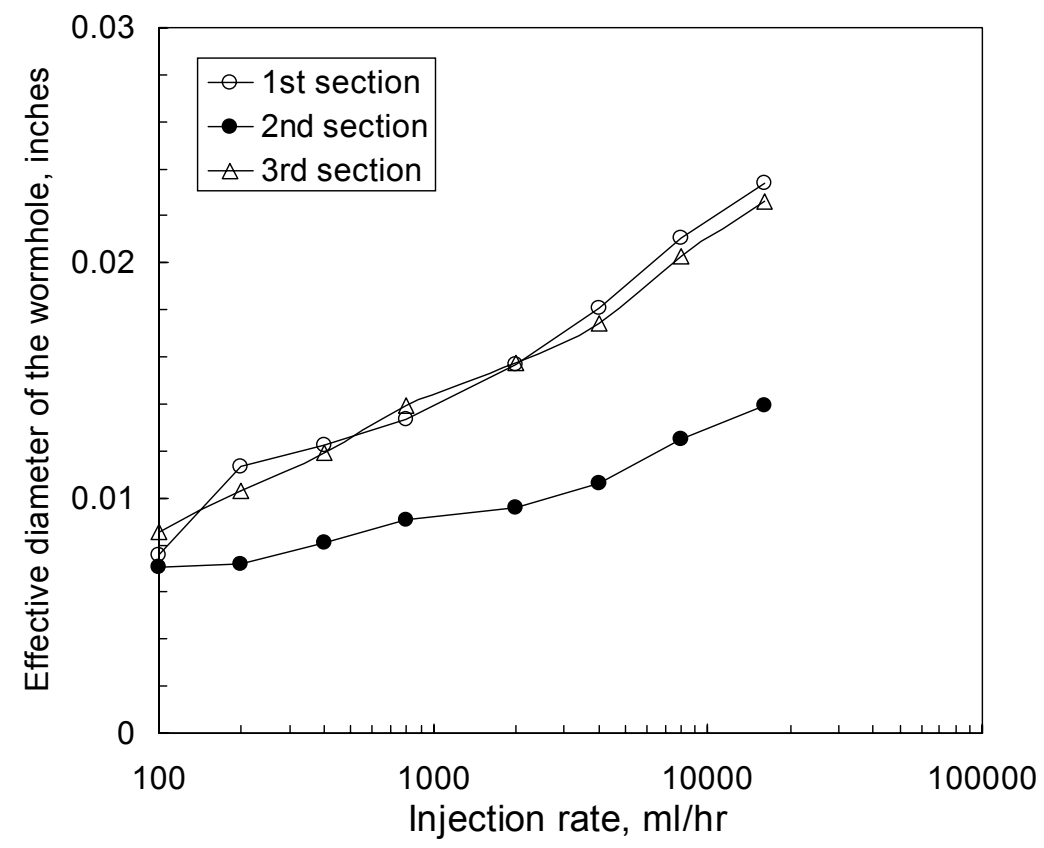

Fig. 4-Calculated wormhole diameters versus brine injection rate after gel placement.

In summary, the pressure gradients during gel extrusion were similar in two 0.08-in.-wide fracture sections, even though they were separated by a 0.02 -in.-wide fracture section. The constriction associated with the middle fracture section may have inhibited gel washout during the first pulse of brine injection after gel placement. However, during subsequent phases of brine injection, the constriction did not inhibit washout in the upstream fracture section any more than in the downstream section. 


\section{REFERENCES}

1. Seright, R.S, Liang J., Lindquist, B.W., and Dunsmuir, J.H.: "Characterizing Disproportionate Permeability Reduction Using Synchrotron X-Ray Computed Microtomography," paper 71508 presented at the 2001 SPE Annual Technical Conference and Exhibition, New Orleans, Sept. 30-Oct. 3.

2. Seright, R.S.: "Conformance Improvement Using Gels," Quarterly Technical Progress Report NM PRRC 02-01, U.S. DOE Contract DE-FC26-01BC15316, (Jan. 2002).

3. Seright, R.S.: "Using Chemicals to Optimize Conformance Control in Fractured Reservoirs," Annual Technical Progress Report (U.S. DOE Report DOE/BC/15110-2), U.S. DOE Contract DE-AC26-98BC15110 (Sept. 1999) 20-21.

4. Bird, R.B., Stewart, W.E., and Lightfoot, E.N.: Transport Phenomena, John Wiley \& Sons, New York (1960) 11, 42-63. 